\title{
Direkt ve indirekt kompozit yüzeylere metal braketlerin bağlanma dayanıklılığının değerlendirilmesi
}

\author{
Mehmet Deniz(0000-0002-0683-7720) ${ }^{\alpha}$, Emire Aybüke Erdur(0000-0002-1887-8474) ${ }^{\alpha}$, Mehmet Akın(0000-0003-0776-7653) $^{\beta}$
}

Selcuk Dent J, 2020; 7: 326-333 (Doi: 10.15311/selcukdentj.722336)

Basvuru Tarihi: 17 Nisan 2020 Yayına Kabul Tarihi: 12 Ağustos 2020

Öz

Direkt ve indirekt kompozit yüzeylere metal braketlerin bağlanma dayanıklıı̆ıının değerlendirilmesi

Amaç: Bu çalışmada, farklı kompozit yüzeylere (direct ve indirekt) uygulanan farklı pürüzlendirme yöntemlerinin yüzeyde oluşturduğu pürüzlülük ve metal braketlerin bağlanma dayanıklıı̆ı üzerine olan etkisi değerlendirilmiştir.

Gereç ve Yöntemler: Çalışmamızda direkt ve indirekt olmak üzere 2 farklı tipte kompozit diskler ve çekilmiş alt keser dişler kullanıldı. Kompozit grupları oluşturmak amacıyla direkt ve indirek kompozitin her birinden 60 adet olmak üzere toplamda 120 kompozit disk üretici talimatlarına göre hazırlandı. Kompozit diskler uygulanacak farklı pürüzlendirme yöntemlerine göre, 4 alt gruba ayrıldı. Bu gruplar; ortofosforik (OF) asit, kumlama, frezle pürüzlendirme yapılan ve hiçbir işlem uygulanmayan kontrol grubu olarak belirlendi. Ayrıca, makaslama bağlanma dayanımı karşılaştırmak için yüzeyi OF asidi ile pürüzlendirilmiş diş grubu oluşturuldu. Bütün kompozit disklerin pürüzlülüğü profilometre cihazı ile yüzeyler pürüzlendirilmeden önce ve sonra ölçüldü. Braketler yapıştııldıktan sonra, örneklere termal siklus uygulandı ve makaslama bağlanma dayanımı testi yapıldı. Kompozit yüzeylerde oluşan değişiklikler stereomikroskop ve tarayıcı elektron mikroskobu (SEM) ile incelendi. İstatiksel değerlendirme için, iki yönlü ANOVA, Tukey HSD ve Wilcoxon signed rank testleri kullanıldı.

Bulgular: Direkt ve indirekt kompozitler arasında makaslama bağlanma dayanımı değerlerinde anlamlı bir fark bulunmadı $(p>0.05)$. Kumlama ile pürüzlendirilen direkt kompozit gruplarında pürüzlülük değerlerinin, indirekt gruptaki değerlerden anlaml derecede daha yüksek bulundu $(p<0.05)$. OF asit ve frez uygulanan yüzeyler arasında istatistiksel olarak fark bulunmadı $(p>0.05)$. Frez yöntemi, hem bağlanma dayanımı, hem de pürüzlülük değerlerinde en yüksek sonuçları gösterdi $(p<0.05)$. Kompozit yüzeylerin SEM görüntüleri de bu bulguları destekledi.

Sonuç: Bu çalışmanın sınırlamaları dahilinde, sonuçlarımız frez uygulamasının ortodontide kompozit yüzeyleri pürüzlendirmede etkili ve güvenilir bir yöntem olduğunu gösterdi.

\section{ANAHTAR KELIMELER}

Kompozit yüzeyler, metal braket, SBS, SEM, yüzey pürüzlülüğü

Ortodonti kliniklerinde tedavi edilen yetişkin hasta sayısındaki artış, ortodontistler için yeni problemler ortaya çıkarmaktadır. Yaşla birlikte çürük ve madde kaybına bağlı olarak restorasyon sayısı da artmaktadır. Dişlerin kompozit rezin, amalgam ve porselen gibi çeşitli

\section{ABSTRACT}

Evaluation of shear bond strength of metal brackets on direct and indirect composite surfaces

Background: The present study aimed to evaluate the effect of different roughening techniques applied on different composite surfaces (direct and indirect) on the surface roughness and shear bond strength (SBS) of metal brackets.

Methods:In our study, two different types of composite discs as direct and indirect, and extracted lower incisors were used. In a total of 120 discs including 60 from each of the direct and indirect composites were prepared. In each group, the following 4 subgroups were prepared:orthophosphoric acid,sandblasting,diamond burr, and control group with no treatment.Also, 15 lower teeth on which surface was roughened with orthophosphoric acid were added to compare SBS. All composite discs were evaluated using a profilometer before and after roughening the surfaces. After brackets were bonded, the samples were stored in thermocycled and SBS testing was performed. The surface of the composite discs was evaluated with stereomicroscope and and SEM. Data were analyzed using the Wilcoxon signed-rank test, two-way ANOVA, and Tukey-HSD test $(p<0.05)$.

Results: No significant difference in SBS values was found between the direct and indirect composites $(p>0.05)$. Roughness values of direct composite discs roughened by sandblasting were found to be higher than those in the indirect group $(p<0.05)$. No significant difference was found between orthophosphoric acid and burr application $(p>0.05)$. The diamond bur showed the highest values in both SBS and roughness values $(p<0.05)$. SEM images of composite surfaces also supported these findings $(p<0.05)$.

Conclusion:Within the limitations of this study, our results showed that burr application is an effective and reliable method for roughening composite surfaces in orthodontics.

\section{KEYWORDS}

Composite surface, metal bracket, SBS, SEM, surface roughness

restoratif materyallerle restore edilmesi sebebiyle ortodontistler, bu materyallere sabit ortodontik ataçmanların yapıştırımasında zorluklarla karşılaşmaktadır. Bu yüzeylerde ataçmanların bağlanma dayanımını arttırmak için çeşitli mekanik

\footnotetext{
${ }^{\alpha}$ Necmettin Erbakan Üniversitesi Diş Hekimliği Fakültesi Ortodonti Anabilim Dalı, Konya

${ }^{\beta}$ Alanya Alaaddin Keykubat Üniversitesi Diş Hekimliği Fakültesi Ortodonti Anabilim Dalı, Alanya, Antalya
} 
ve kimyasal yöntemler önerilmiştir. ${ }^{1-8}$ Ancak bu yüzeylerin pürüzlendirilmesinde, henüz üzerinde fikir birliği sağlanmış bir protokol yoktur..$^{9,10}$

Anterior dişlerdeki aşırı çürükler, diastema ve çapraşıklıklar, hipoplaziler, florozis gibi konjenital ve edinsel nedenlerle ortaya çıkan anomaliler, prenatal ve postnatal antibiyotik alımı veya geçirilen hastalıklara bağlı olarak renklenmiş, abraze ve kırılmış dişler hastalarda estetik problemler yaratmaktadır. Geleneksel tedavi yaklaşımında bu dişler kuronlanmaktadır. Ancak bu işlem için diş kesimi yapılırken dişten fazla miktarda doku kaybı olması, yapılan kuronlar estetik olsa da dişeti ve çevre dokularda harabiyetler oluşturması nedeniyle kuronlara alternatif olarak laminate veneerler kullanılmaya başlanmıştır. ${ }^{11,12}$ Anterior dişlerin labial yüzeyine ince bir akril rezin, kompozit rezin veya porselen materyalinin uygulanması ile elde edilen laminate veneerler estetik ve fonksiyonel düzeltmelerin en konservatif olan yöntemidir ve dişeti sağlığı açısından da daha güvenilirdir. ${ }^{12}$

Kompozit veneerler direkt veya indirekt yöntemle, farklı içerikte kompozitlerle yapılmaktadır. ${ }^{13}$ Kompozit materyalinin içeriği de ortodontik ataçmanların bağlanma gücünü etkilemektedir. ${ }^{10}$ Fırınlanabilir kompozitlerin kullanıldığı indirekt yöntemde mikrohibrit kompozitler kullanılırken, direkt yöntemde evrensel restoratif materyal olarak tanıtılan nanofill kompozitler kullanılmaktadır. Bu kompozitlerin dayanıklılığı ve estetik özellikleri hem anterior hem de posterior bölgede kullanımasına izin verir. ${ }^{13}$ Restorasyon materyali türlerinin farklı yüzey özelliklerine sahip olması sebebiyle farklı yüzey pürüzlendirme yöntemlerinin uygulanması gerekmektedir.

$\mathrm{Bu}$ bilgiler ışığında çalışmamızın amacı, direkt ve indirekt kompozit yüzeylerde bonding işlemini gerçekleştirmek için en uygun yüzey pürüzlendirme yöntemini bulmaktır.

\section{GEREÇ VE YÖNTEM}

Çalışmamız, Necmettin Erbakan Üniversitesi Diş Hekimliği Fakültesi Araştırma Laboratuvarı'nda gerçekleşmiştir. Çalışmamızın yürütülebilmesi için, Necmettin Erbakan Üniversitesi lokal etik kurulundan 2019/10 numaralı etik kurul kararı alınmıştır. Direkt yöntemle yapılan nano-hibrit (Aelite ${ }^{\mathrm{TM}}$ Aesthetic Enamel, BISCO Dental Products, Schaumburg, Illinois, USA) ve indirekt yöntemle yapılan mikro-hibrit kompozit rezinler (Tescera ${ }^{\mathrm{TM}}$, BISCO Dental Products, Schaumburg, Illinois, USA) kullanılarak, her grupta 60 adet olmak üzere toplam 120 adet $6 \mathrm{~mm}$ çapında, 2 $\mathrm{mm}$ kalınlığında silindir disk üretildi. Örnekler, pürüzlendirme öncesi ve sonrasında profilometre cihazıyla (ölçme ucu; $2 \mu \mathrm{m}$, baskı kuvveti; $0.7 \mathrm{mN}$, hızı;
$0.5 \mathrm{~mm} / \mathrm{sn}$ ) (MarSurf PS1, Mahr GmbH, Göttingen, Germany) incelendi. Braketin yapıştırılacağı bölgeye, OF asit, , su ile yıkandı. Örnekler, 15 mm iç çapı olan silindir kalıplar içine soğuk akrilikle gömüldü. Direkt ve indirekt kompozit diskler, kendi içlerinde rastgele 4 alt gruba ayrıldı. Grup 1, kontrol grubu olarak belirlenerek pürüzlendirme işlemi yapılmadı. Grup 2, örnek yüzeylere 2.5 bar basınçla, $50 \mu \mathrm{m}$ boyutunda $\mathrm{Al}_{2} \mathrm{O}_{3}$ partikülü püskürten bir kumlama cihazıyla kumlama yapıldı. Grup 3, kompozit yüzeyine \% 37'lik konsantrasyona sahip OF asit (Panora 200, IMICRYL, Konya, Türkiye) 30 sn boyunca uygulandı. Grup 4, 151-213 $\mu \mathrm{m}$ grenli silindirik elmas frezle (Meisinger, Hager \& Meisinger $\mathrm{GmbH}$, Neuss, Almanya) pürüzlendirme yapıldı. Ayrıca, son altı ay içinde çekilmiş 15 adet çürüksüz alt keser diş, kompozit yüzeylerin makaslama bağlanma değerlerini karşılaştırmak için ortofosforik (OF) asit (\% 37'lik OF, 30 sn) uygulanan diş grubu olarak dahil edildi.

Braketler (Mini Master, American Orthodontics, USA) primer (Transbond ${ }^{\mathrm{TM}} \mathrm{XT}$ primer, 3M Unitek, Monrovia, California, USA) ve yapıştırıcı kompozit (Transbond ${ }^{\mathrm{TM}} \mathrm{XT}$ Light Cure Adhesive, 3M Unitek, Monrovia, California, USA) kullanılarak yüzeylere yerleştirildi. Örnekler, braketler yapıştırıldıktan sonra 24 saat, $37{ }^{\circ} \mathrm{C}$ 'lik distile suda bekletildi ve daha sonra örnekler 5-55 ${ }^{\circ} \mathrm{C}$ ' deki su tanklarında 30'ar sn, tanklar arası transfer süreci $15 \mathrm{sn}$ olacak şekilde termal siklus cihazına (Thermocycler THE1100, SD Mechatronik GMBH, Feldkirchen-Westerham, Germany) alındı ve bu döngü 5000 kez tekrarlandı. Makaslama testi, universal test cihazı (BMT-10E, Besmak, Ankara, Türkiye) ile hareketli ucun hızı, 0.5 $\mathrm{mm} / \mathrm{dk}$ olarak yapıldı. Örneklere, braket örnekten ayrılana kadar tek noktadan kuvvet uygulanarak kopma anındaki kuvvet değeri Newton cinsinden kaydedilerek "Mpa $=\mathrm{N} / \mathrm{mm}^{2}$ " formülüyle megapascal (MPa) birimine çevrildi. Braketlerin kopma bölgelerinin incelenip skorlanması için örnekler stereomikroskop (Olympus SZ 40, Olympus Optical Co. Ltd, Tokyo, Japonya) ile x20 büyütmede görüntülendi. Makaslama testi sonrasında birbirinden ayrılan diş, kompozit ve braket yüzeyleri incelendi ve kopma tipleri adeziv (yapıştırıcı ve kompozit/diş arasında tam ayrılma), koheziv (kompozitin kendi içinde olan ayrılması) ve karma (adeziv ve koheziv ayrılmanın birlikte görülmesi) olarak kategorize edildi. Örneklerin yüzey profil görüntüleri SEM (Zeiss Evo LS 10, Carl Zeiss AG, Oberkochen, Germany) de incelenerek uygulanan yöntemler kıyaslandı.

Çalışmada elde edilen verilerin istatistiksel analizi, istatistik paket programı (SPSS 23 for Windows, SPSS Inc., Chicago, Illinois, USA) kullanılarak gerçekleştirildi. İki bağımsız grup arasında değerlerin ortalamalarına göre farklılık olup olmadığı bağımsız örneklem t-testi ile, iki bağımlı grup arasında ortalamalarına göre farklılık olup olmadığı ise bağımlı örneklem t-testi ile incelendi. Kompozit yüzeylerde pürüzlendirme yöntemlerinin, pürüzlülüğe ve makaslama kuvvetlerine etkisini bulmak 
amacıyla iki yönlü varyans analizi, yöntemler arası fark olup olmadığı ise Tukey HSD testi ile incelendi. Kopma tipleri ki-kare testi ile değerlendirildi. Analizlerde istatistiksel anlamlılık düzeyi $p<0.05$ olarak kabul edildi.

\section{BULGULAR}

Grupların ortalama pürüzlülük farkı ve standart sapma değerleri Tablo 1'de verildi.

Tablo 1.

Grupların yüzey pürüzlülük değerlerinin ortalama ve standart sapma değerleri

\begin{tabular}{|lccc|}
\hline Yöntem & $\begin{array}{c}\text { Direkt }(\mathbf{n = 1 5}) \\
\text { Ort } \pm \text { SS }\end{array}$ & $\begin{array}{c}\text { Indirekt }(\mathbf{n = 1 5}) \\
\text { Ort } \pm \mathrm{SS}\end{array}$ & $\begin{array}{c}\text { Toplam }(\mathbf{n = 3 0}) \\
\text { Ort } \pm \mathrm{SS}\end{array}$ \\
\hline Kumlama & $2.11 \pm 0.50$ & $1.37 \pm 0.66$ & $1.74 \pm 0.69^{\mathrm{a}}$ \\
\hline OF Asit & $0.16 \pm 0.04$ & $0.02 \pm 0.06$ & $0.02 \pm 0.05^{\mathrm{b}}$ \\
\hline $\begin{array}{l}\text { Frez } \\
\text { *Farklı harfler, Tukey HSD Post-Hoc testine göre istatistiksel farkllıkları } \\
\text { göstermektedir. }\end{array}$ & $2.62 \pm 0.64$ & $3.01 \pm 0.91$ & $2.81 \pm 0.80^{\mathrm{c}}$ \\
\hline
\end{tabular}

Direkt kompozit yüzeylerde en yüksek pürüzlülük değeri ortalaması frez uygulanan grupta $(2.62 \mu \mathrm{m})$ bulundu. Bu grubu, kumlama uygulanan grup $(2.11 \mu \mathrm{m})$ takip etti. OF Asit uygulanan grup $(0.16$ $\mu \mathrm{m})$ ise, en düşük ortalamaya sahip grup oldu (Tablo 1). Indirekt kompozit yüzeylerde ise en yüksek pürüzlülük değeri ortalaması frez uygulanan grupta $(3.01 \mu \mathrm{m})$ bulundu. Bu grubu, kumlama uygulanan grup $(1.37 \mu \mathrm{m})$ takip etti. OF Asit uygulanan grup $(0.02 \mu \mathrm{m})$ ise, en düşük ortalamaya sahip grup oldu (Tablo 1).

Kompozit yüzeylere yapılan yüzey işlemlerinin pürüzlülük üzerine olan etkisi, iki yönlü varyans analizine göre incelendiğinde farklı kompozit sistemlerinin yüzey pürüzlülüğünü etkilemediği $(p>0.05)$, pürüzlendirme işlemlerinin yüzey pürüzlülüğünü etkilediği $(p<0.05)$, kompozit sistemleri ve yüzey işlemleri arasında da etkileşim olduğu gözlendi ( $p=0.001$ ) (Tablo 2). Elde edilen bu sonuçlara göre test değerine etki eden pürüzlendirme işlemlerinden en az bir tane işleminin yüzey pürüzlülüğüne etkisinin farklı olduğunu gösterdi. Tukey HSD sonuçlarına göre; kumlama uygulanan grup ile frez ve OF asit uygulanan gruplar arasındaki fark istatistiksel olarak anlamlı bulundu $(p<0.05)$. OF asit uygulanan grup ile frez ve kumlama uygulanan gruplar arasındaki fark istatistiksel olarak anlamlı bulundu $(p<0.05)$. Frez uygulanan grup ile kumlama ve OF asit uygulanan gruplar arasındaki fark istatistiksel olarak anlamlı bulundu $(p<0.05)$ (Tablo 2).
Tablo 2.

\section{Yüzey pürüzlük değerlerinin iki yönlü varyans analizi sonuçları}

\begin{tabular}{lcccccc}
$\begin{array}{l}\text { Etki Faktörleri } \\
\text { (Varyasyon } \\
\text { Kaynağı) }\end{array}$ & sd & KT & KO & F & p & Kısmi Eta-Kare \\
\hline Yüzey & 1 & 0.304 & 0.304 & 0.945 & 0.334 & 0.011 \\
\hline Yöntem & 2 & 119.326 & 59.663 & 185.366 & $0.000^{*}$ & 0.815 \\
\hline Yüzey * Yöntem & 2 & 4.917 & 2.459 & 7.639 & $0.001 * *$ & 0.154 \\
\hline
\end{tabular}

${ }^{*} p<0.05,{ }^{* *} p<0.001$, sd: Serbestlik Derecesi, KT: Kareler Toplamı, KO: Kareler Ortalaması, F: iki Yönlü Varyans Analizi (ANOVA), p:Anlamllik Düzeyi

Kompozit yüzeylere yapılan yüzey işlemlerinin makaslama bağlanma dayanımı üzerine olan etkisinin sonuçları Tablo 3'te verildi. İki yönlü varyans analizine göre; farklı kompozit sistemlerinin makaslama bağlanma dayanımını etkilemediği $(p>0.05)$, pürüzlendirme işlemlerinin makaslama bağlanma dayanımını etkilediği $(p<0.05)$, kompozit sistemleri ve yüzey işlemleri arasında da etkileşim olduğu gözlenmedi $(p>0.05)$.

Tablo 3.

Makaslama bağlanma dayanımı değerlerinin iki yönlü varyans analizi sonuçları

\begin{tabular}{lcccccc}
$\begin{array}{l}\text { Etki Faktörleri } \\
\text { (Varyasyon } \\
\text { Kaynağı) }\end{array}$ & sd & KT & KO & F & p & Kısmi Eta-Kare \\
\hline Yüzey & 1 & 5.799 & 5.799 & 0.641 & 0.425 & 0.005 \\
\hline Yöntem & 3 & 1509.509 & 503.17 & 55.619 & $0.000^{*}$ & 0.57 \\
\hline $\begin{array}{l}\text { Yüzey * Yöntem } \\
\text { * } p<0.05,{ }^{* *} p<0.001, \text { sd: Serbestlik Derecesi, KT: Kareler } \\
\text { Varyans Analizi (ANOVA), }\end{array}$ & 3 & 72.051 & 24.017 & 2.655 & 0.51 & 0.059 \\
\hline
\end{tabular}

Direkt kompozit yüzeylerde makaslama bağlanma dayanımı değeri en yüksek frez uygulanan grupta (12.64 MPa) bulundu. Bu grubu, sırasıyla OF asit uygulanan diş grubu (12.04 $\mathrm{MPa}$ ) ve kumlama uygulanan grup (10.65 $\mathrm{MPa}$ ) takip etti. OF Asit uygulanan grup (5.18 MPa) ve kontrol grubu (5.85 MPa) en düşük ortalamaya sahip gruplar oldu (Tablo 4). İndirekt kompozit yüzeylerde makaslama bağlanma dayanımı değeri karşılaştırmasında frez uygulanan grupta (15 $\mathrm{MPa}$ ) makaslama bağlanma dayanımı değeri ortalaması en yüksekti. Bu grubu, sırasıyla OF asit uygulanan diş gurubu (12.04 MPa) ve kumlama uygulanan grup (10.20) takip etti. OF Asit uygulanan grup (6.62 MPa) ve kontrol grubu (4.25 $\mathrm{MPa}$ ) en düşük ortalamaya sahip gruplar oldu (Tablo 4). Tüm yüzeylerde makaslama bağlanma dayanım değerlerinde, frez uygulanan grup ile OF asit uygulanan diş grubu arasında istatistiksel olarak anlamlı bir fark görülmezken $(p>0.05)$, kumlama uygulanan grup, kontrol grubu ve OF asit uygulanan gruplarla karşılaştırıldığında fark istatistiksel olarak anlamlı bulundu $(p<0.05)$. Kontrol grubu ile OF asit uygulanan grup arasında istatistiksel olarak anlamlı bir fark görülmezken ( $p>0.05)$, OF asit uygulanan diş grubu, frez ve kumlama uygulanan gruplar arasında fark istatistiksel olarak anlamlı bulundu $(p<0.05)$. Kumlama uygulanan grup ile diğer gruplar arasında fark istatistiksel olarak anlamlı bulundu $(p<0.05)$ (Tablo 4). 
Tablo 4.

\section{Grupların makaslama bağlanma dayanımı değerlerinin ortalama ve standart sapma değerleri}

\begin{tabular}{|c|c|c|c|}
\hline Yöntem & Yüzey & Ort \pm SS & Ort \pm SS (Yöntem) \\
\hline \multirow{2}{*}{ Kontrol } & Direkt $(n=15)$ & $5.85 \pm 2.01$ & $5.05 \pm 2.09^{d}$ \\
\hline & İndirekt $(n=15)$ & $4.25 \pm 1.89$ & \\
\hline \multirow{2}{*}{ Kumlama } & Direkt $(n=15)$ & $10.65 \pm 2.89$ & $10.42 \pm 3.50^{\mathrm{e}}$ \\
\hline & İndirekt $(n=15)$ & $10.20 \pm 4.12$ & \\
\hline \multirow{3}{*}{ OF Asit } & Direkt $(n=15)$ & $5.18 \pm 2.02$ & $5.90 \pm 2.66^{d}$ \\
\hline & İndirekt $(n=15)$ & $6.62 \pm 3.08$ & \\
\hline & Diş $(n=15)$ & $12.04 \pm 2.91$ & $12.04 \pm 2.91^{\mathrm{f}}$ \\
\hline \multirow{2}{*}{ Frez } & Direkt $(n=15)$ & $12.64 \pm 2.98$ & $13.82 \pm 3.77^{f}$ \\
\hline & İndirekt $(n=15)$ & $15 \pm 4.19$ & \\
\hline
\end{tabular}

*Farklı harfler, Tukey HSD Post-Hoc testine göre istatistiksel farkllıkları göstermektedir.

Toplam 60 adet direkt kompozit örnekten 24 (\% 40) tanesi adeziv kopma gösterirken, 5 (\% 8.3) tanesi koheziv kopma, 31 (\% 51.7) tanesi karma kopma gösterdi. Adeziv tip kopma tüm gruplarda görülürken 10 (\% 16.7) örnek ile en fazla kontrol grubunda görüldü. Karma tip kopma tüm gruplarda görülürken 8 (\% 13.3) örnekle en fazla OF asit grubunda görüldü. Koheziv kopma OF asit grubu dışında tüm gruplarda görülürken 2'şer örnek ile en fazla kontrol ve frez gruplarında görüldü. ARI skorlaması sonuçlarına göre; toplam 60 adet indirekt kompozit örnekten 35 (\% 58.3) tanesi adeziv kopma gösterirken, 1 (\% 1.7) tanesi koheziv kopma, 24 (\% 40) tanesi karma kopma gösterdi. Adeziv tip kopma tüm gruplarda görülürken 11 (\% 18.3) örnek ile en fazla kontrol grubunda görülmüştür. Karma tip kopma tüm gruplarda görülürken 9 (\% 15) örnekle en fazla frez grubunda görülmüştür. Koheziv kopma, 1 (\% 1.7) örnekle sadece frez grubunda görüldü. Uygulanan ki-kare testi sonucunda kopma tipleri ile yüzeyler arasında istatistiksel olarak anlamlı bir ilişki görülmemiştir $(p>0.05)$. Pearson korelasyon testine göre, hem direkt kompozit grubu $(r=0.746$; $\mathrm{p}<0.001$ ), hem de indirekt kompozit grubu $(r=0.718 ; p<0.001)$ için bağlanma dayanımı ile yüzey pürüzlülüğü arasında yüksek düzeyde pozitif yönde anlamlı doğrusal bir ilişki olduğu görüldü.

SEM görüntüleri kontrol grubuyla karşılaştıııldığında direkt kompozit yüzeylerde kumlama ve frezle yapılan uygulanan yüzey pürüzlendirme yöntemlerinin etkin olduğu görüldü (Şekil 1). Kumlama ile yapılan pürüzlendirmenin frezle yapılan pürüzlendirmeye kıyasla daha sığ ve düzenli olduğu görüldü. OF asit ile pürüzlendirilen yüzey kontrol grubuyla benzer yüzey topoğrafisi gösterdi.
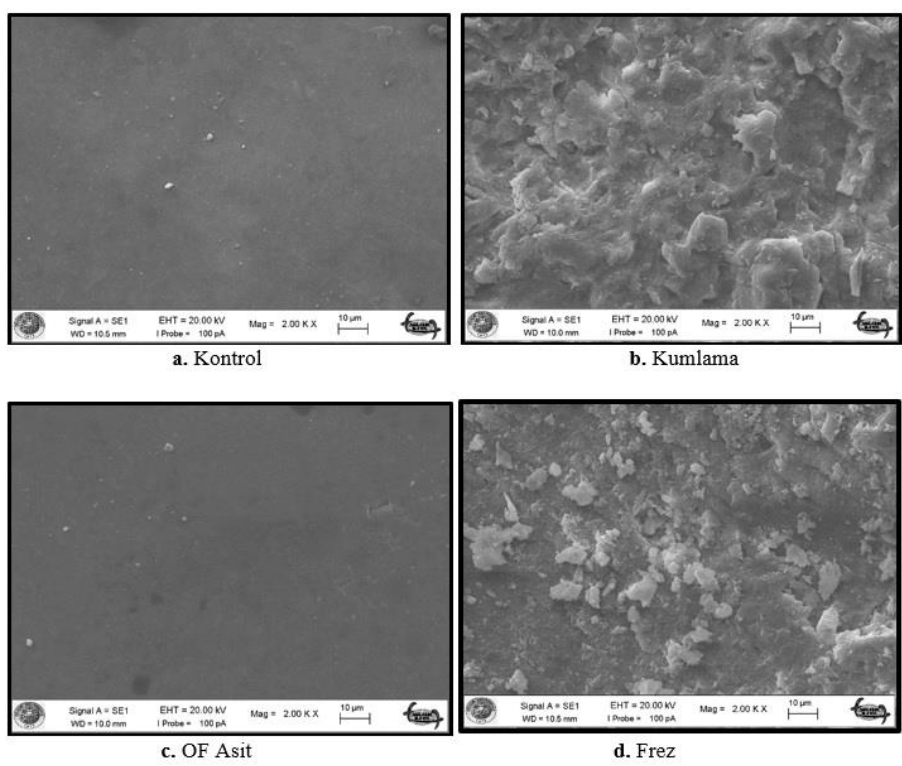

Şekil 1.

Direkt kompozit yüzeylerin SEM görüntüleri

SEM görüntüleri kontrol grubuyla karşılaştırıldığında indirekt kompozit yüzeylerde kumlama ve frezle yapılan uygulanan yüzey pürüzlendirme yöntemlerinin etkin olduğu görüldü (Şekil 2). Kumlama ile yapılan pürüzlendirmenin frezle yapılan pürüzlendirmeye kıyasla daha sığ, keskin kenarlı ve düzenli olduğu görüldü. OF asit ile pürüzlendirilen yüzey control grubuyla benzer yüzey topoğrafisi gösterdi. SEM görüntüleri kontrol grubuyla karşılaştırıldığında OF asidin mine yüzeyi üzerinde düzensiz profilli pürüzlendirme oluşturduğu görüldü.
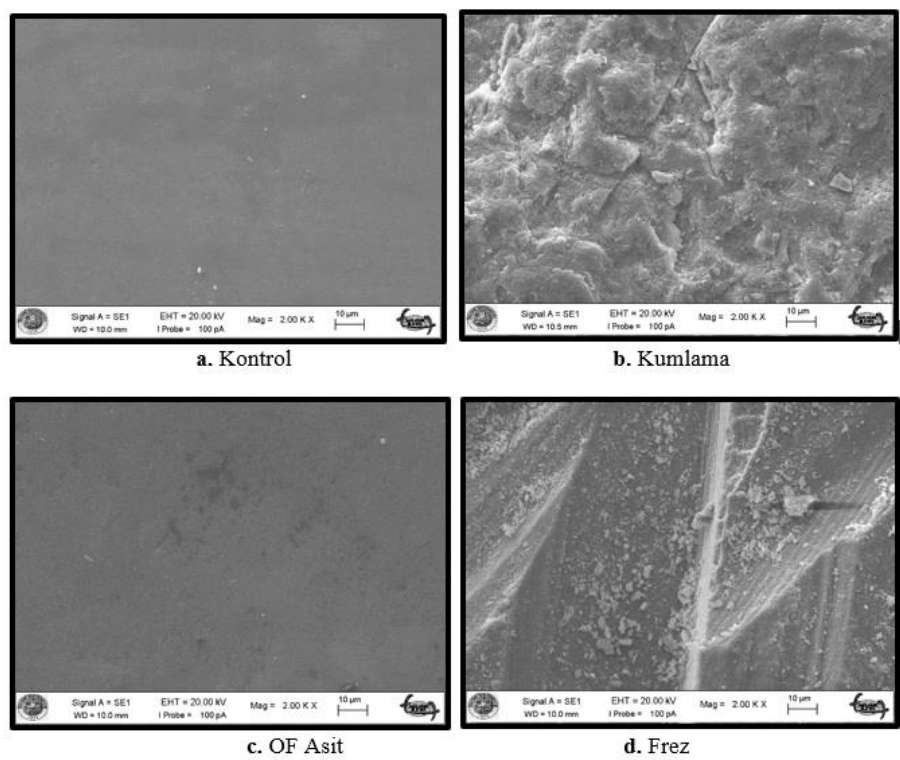

Şekil 2.

İndirekt kompozit yüzeylerin SEM görüntüleri 


\section{TARTIŞMA}

Ortodonti kliniğinde tedavisi yapılan hastaların yaş ortalamasındaki artış, restorasyonlu diş sayısındaki artışı da beraberinde getirmektedir. Kompozit rezin, amalgam ve porselen gibi çeşitli materyallerle yapılan restorasyonların yüzey yapısı ile mine yüzey yapısı farklılık göstermektedir. Bu sebeple yapıştırma alanını pürüzlendirmek için çeşitli mekanik ve kimyasal yöntemler denenmiştir ${ }^{1-8}$. Ancak restorasyonlu yüzeyleri pürüzlendirmede henüz üzerinde fikir birliği sağlanmış bir protokol yoktur. ${ }^{9,10}$

Kompozit rezinler kolay uygulanabilir, düşük maliyetli ve farklı renk seçeneklerine sahip olduğu için tatmin edici düzeyde estetik olması sebebiyle ön bölge restorasyonlarında sıklıkla kullanılan bir restorasyon materyalidir. Literatürde yer alan mevcut çalışmalarda ortodontik braketlerin kompozit yüzeylere bağlanma dayanımını inceleyen birçok çalışma varken, farklı pürüzlendirme yöntemleriyle direkt ve indirekt tekniklerle üretilen kompozit restorasyonlar ve diş yüzeyine metal braketlerin bağlanma dayanımını araştıran az sayıda çalışma vardır. Yaptığımız bu çalışmamın amacı farklı yöntemlerle pürüzlendirilen farklı kompozit yüzeylerin bağlanma dayanımı arasında fark olup olmadığını araştırmak ve kompozit yüzeye braket yapıştırmak için bağlanma dayanımı açısından en etkin yöntemi bulmaktır.

Kompozit restorasyonların fiziksel özelliklerinde önemli iyileşmeye neden olan indirekt kompozit rezin sistemlerinde ve laboratuvar polimerizasyon tekniklerinde kaydedilen ilerlemelere rağmen, bu restorasyonların bağlanma direnci hala bir problem olmaktadır. $^{14}$ Azalan bağ direncinin nedenleri, polimerizasyon derecesinin arttırıması ve ışık, yüksek sıcaklık, basınç ve elektromanyetik yöntemler gibi ikincil polimerizasyon yöntemleriyle bağlanma için gereken reaksiyona girmemiş metakrilat gruplarının azaltılması olabilmektedir. ${ }^{15}$ Yapılan bir çalışmada, ışıkla sertleştirmede polimerizasyon derecesinin \% 42-45, laboratuvarda ikincil sertleştirme sonrasında ise \% 68 olduğu bildirilmiştir. ${ }^{16}$ Özcan ve ark. ${ }^{17}$, nano-hibrit ve mikro-hibrit kompozit rezinlerin pürüzlendirme etkinliği üzerine yaptığı çalışmada, kompozit tipinin bağlanma direncini önemli derecede etkilemediğini bildirmişlerdir. $\mathrm{Bu}$ çalışmayla uyumlu olarak çalışmamızda da direkt kompozit ile indirekt kompozit yüzey pürüzlülük değerlerinde istatistiksel olarak anlamlı bir fark görülmemiştir.

Farklı kompozit türlerinin dahil edildiği bir çalışmada, ${ }^{18}$ nano-hibrit kompozitin bağlanma dayanımının, mikro dolduruculu kompozite göre önemli bir fark olmasa da daha yüksek olduğu bildirilmiştir. Yapılan başka bir çalışmada,$^{19}$ mikro-hibrit kompozit, nanofill kompozitlere kıyasla daha iyi bir bağlanma direncine sahipken, nanofill ve nano-hibrit tiplerinin arasında önemli bir fark olmadığı sonucu ortaya çıkmıştır. Çalışmamızda direkt ile indirekt kompozit arasında makaslama bağlanma dayanımı açısından kontrol grubunda, kumlama ve frez yöntemindeki değerlerin ortalamalarına göre istatistiksel olarak anlamlı bir farklılık görülmemiştir. OF asit uygulanan gruplar arasında, diş grubunun değerlerinin ortalaması direkt ve indirekt kompozit değerlerinin ortalamalarından anlamlı derecede daha yüksek bulunmuştur.

Kompozit yüzeylerle braket arasındaki bağlanmayı güçlendirmek için çeşitli teknikler önerilmiştir. Kompozit yüzey ve braket arasındaki bağlanma dayanımının geliştirilmesi adına mekanik kilitlenmeyi sağlamak için yüzey pürüzlülüğünün arttırıması, yüzey ıslanabilirliğini artırmak ve kimyasal bağlamayı sağlamak için kompozit yüzeyin doldurucu içermeyen rezin bağlama ajanları ile kaplanması gerekmektedir. ${ }^{21}$

OF asit ile pürüzlendirme, normalde kavite kenarındaki mine ve / veya dentin için yeterli bağlanma kuvvetleri elde etmek için yapılması gereken kompozit onarım prosedürlerinde rutin bir adımdır. Bununla birlikte birçok çalışmada, kompozit-kompozit yapıştırma işlemine katkısının sınırlı olduğu bildirilmiştir. ${ }^{22-25}$ Uygulamanın toplam yüzey alanını arttırdığı gösterilmiş olsada, ${ }^{26}$ bağlanma direncinde gelişme gözlenmemiştir. ${ }^{27,28} \mathrm{Bazı}$ çalışmalarda da OF asit uygulamasının kompozit yüzeyde pürüzlülüğe etki etmediği bildirilmiştir. ${ }^{29,30}$ Mikroskopla gözlem yapılan bir çalışmada OF asidin kompozit yüzeyinin özelliklerini değiştirmediği belirtilmiştir. ${ }^{31}$ Çalışmamızdaki örneklerin kopma tiplerinin değerlendirmesinin sonucunda, OF asit gruplarında kompozit-braket ara yüzünde başarısızlığının meydana geldiğini göstermiştir. Bu, kompozit ile braket arasında zayıf bir bağlantı olduğunu göstermektedir.

Frez uygulamasını inceleyen bir çalışmada, mavi kuşaklı elmas frezin (Ra: $3.36 \mu \mathrm{m}$ ) kırmızı kuşaklı elmas frezden (Ra: $1.07 \mu \mathrm{m}$ ) daha yüksek yüzey pürüzlülüğü oluşturduğu ve daha yüksek bağlanma direnci sağladığı bildirilmiştir. ${ }^{32}$ Öte yandan, kumlama gruplarındaki pürüzlülük değerlerinin kırmızı kuşaklı elmas frez uygulamasına göre daha az olduğunu, ancak kumlama işleminden sonra elde edilen bağlanma kuvvetlerinin önemli ölçüde daha yüksek olduğunu bildiren araştırmacılar vardır. ${ }^{32}$ Elmas frezlerle işlenen yüzeylerin daha fazla makroretansiyon özelliği ${ }^{20,22}$, daha düzensiz ${ }^{33}$ ve belli belirsiz mikroretansiyon özelliğ ${ }^{32}$ olduğu görülürken, kumlama, belirgin mikroretansiyon özellikleri olan ${ }^{20,22,34}$ daha homojen yüzeyler oluşturur. ${ }^{32}$ $\mathrm{Bu}$ sebepten, kumlama ile üretilen toplam yapışma yüzey alanı, profildeki $(\mathrm{Ra})$ benzerliklere rağmen elmas frezleri tarafından oluşturulan yüzey alandan daha fazla olmaktadır. ${ }^{33}$ Bununla birlikte, kumlama ile mavi kuşaklı frez uygulamasının benzer bağlanma direnci oluşturduğunu bildiren çalışmalar vardır. ${ }^{20,27}$ Çalışmamızda, kompozit yüzeylerde kumlama ve frezle pürüzlendirme yöntemlerinin etkin bir pürüzlülük sağladığı görülmüştür. 
Kumlama, mikromekanik kilitleme için asit uygulamasından daha mikroretantif alanlar oluşturan pürüzlendirme işlemidir. Bununla birlikte, SEM görüntülerine göre, elmas frez uygulanması kompozit yüzey üzerinde makro ve mikroretantif alanlar yaratır. $\mathrm{Bu}$ uygulamalar yüzeyi kaldırır ve doldurucu partikülleri ortaya çıkarır. Böylece restorasyonun yüzey özelliklerine zarar verir. Bu sebepten dolayı kumlama ve elmas frez gruplarından makaslama bağlanma değerlerinde bir artış beklenmektedir. Çalışmamızda kontrol grubuyla kıyaslandığında kumlama ve frez yöntemindeki makaslama bağlanma değerleri ortalamalarının istatistiksel olarak anlamlı derecede daha yüksek olduğu görülmüş, kumlama uygulanan gruptaki makaslama bağlanma değerleri ortalaması ise frez uygulanan gruptaki makaslama bağlanma değerleri ortalamasından istatistiksel olarak anlamlı derecede daha düşük olduğu bulunmuştur.

Ağız ortamında braketler, makaslama, çekme, burulma veya bu yüklerin bir kombinasyonuna maruz kalır ve bu kuvvetlerin miktarını belirlemek zordur. Reynolds ve von Fraunhofer ${ }^{35}$, maksimum uzun süreli makaslama kuvvetinin ortodontik tedavi için gerek duyulmamasından dolayı, 5.9-7.8 MPa aralığındaki makaslama kuvvetinin çoğu ortodontik tedavi için yeterli olacağını belirtmiştir. Yüksek makaslama bağlanma dayanımının, debonding esnasında minede kırık veya çatlaklara sebep olabileceği ortaya çıkmıştır. Bu nedenle bazı araştırmacılar makaslama bağlanma dayanımının en fazla $20 \mathrm{MPa}$ olması gerektiğini belirtmişlerdir. ${ }^{36,37}$ Yaptığımız çalışmada ise makaslama bağlanma dayanımı değerleri, diş örneklerinde, kumlama ve frez uygulanan kompozit örneklerinde klinik olarak yeterli düzeydeyken OF asit uygulanan ve kontrol grubunda yetersiz bulunmuştur.

Kopma tipleri, adeziv, koheziv ya da karma olmak üzere üçe ayrılır. ${ }^{38,39}$ Kompozit örnekler içerisinde oluşan koheziv kırıkları, yapıstırıcı rezin ile kompozit materyali arasındaki bağlanma düzeyinin kompozitin kendi içindeki bağlanmadan daha güçlü olduğu sonucunu ortaya çıkarır. ${ }^{40}$ Thurmond ve ark. ${ }^{41}$, bağlanma direnci değerinin 13 MPa'ı geçtiği durumlarda kompozit içerisinde koheziv kırıkların oluşacağını bildirmişlerdir. Yaptığımız çalışmada makaslama testinden sonra stereomikroskop ile incelenen direkt kompozit örneklerde en çok karma tip kopma (\% 51.7), indirekt kompozit örneklerde ise en çok adeziv tip kopma (\% 58.3) görülmüştür. Diş örneklerde ise kopmaların hepsi adeziv tiptedir. Hem direkt hem de indirekt kompozit yüzeylerde uygulanan pürüzlendirme yöntemiyle kopma tipleri arasında istatistiksel olarak anlamlı bir ilişki bulunmamıştır.

\section{SONUÇ}

Çalışmamızda kompozit yüzeylere yapıştırdığımız metal braketlerin ortalama bağlanma dayanımları OF asit uygulanan gruplar dışında klinik olarak kabul edilebilir değerlerdedir. Teste tabi tutulan yöntemler arasında OF asit ile pürüzlendirme sonrasında yapıştırılan metal braketler en düşük bağlanma değerlerini göstererek kabul edilebilir sınırların altında kaldığı için kompozit yüzeylere metal braketlerin yapıştırılmasında güvenilir bir yöntem olarak bulunmamıştır. Frezle pürüzlendirme yöntemi, hem makaslama bağlanma dayanımı, hem de yüzey pürüzlülüğü değerlerinde en yüksek sonuçları vermiştir. Kumlama ve frez ile pürüzlendirilen kompozitlerde, makaslama bağlanma dayanıkılığı değerleri klinik olarak yeterli olmasına rağmen ağız içinde kumlama, hastanın sağlığı açısından tehdit oluşturacağı için kompozit yüzeylerin aşındırımasında frez ile pürüzlendirme yöntemini önermekteyiz. 


\section{KAYNAKLAR}

1. Bishara SE, Ajlouni R, Oonsombat C. Bonding Orthodontic Brackets to Composite Using Different Surface Preparations and Adhesive/Primers: A Comparative Study. J World Journal of Orthodontics. 2003; 4(4): 343-7.

2. Viwattanatipa N, Jermwiwatkul W, Chintavalakorn R, Kanchanavasita W. Weibull analysis of bond strength of orthodontic buccal tubes bonded to resin composite surface with various techniques. J Orthodontic Waves. 2010; 69(2): 66-74.

3. Schwartz RE, Tyas M, West V. The bonding of orthodontic brackets to composite resin surfaces. J Australian Dental Journal. 1990; 35(5): 472-3.

4. Lai PY, Woods MG, Tyas MJ. Bond strengths of orthodontic brackets to restorative resin composite surfaces. Aust Orthod J. 1999; 15(4): 235-45.

5. Erdur EA, Basciftci FA. Effect of Ti:Sapphirefemtosecond laser on the surface roughness of ceramics. Lasers Surg Med. 2015a; 47(10): 833-8.

6. Erdur EA, Basciftci FA. Effect of Ti:sapphire laser on shear bond strength of orthodontic brackets to ceramic surfaces. Lasers Surg Med. 2015b; 47(6): 512-9.

7. Akin M, Veli I, Erdur EA, Aksakalli S, Uysal T. Different pulse modes of Er:YAG laser irradiation: effects on bond strength achieved with self-etching primers. J Orofac Orthop. 2016; 77(3): 151-9.

8. Viwattanatipa N, Juntavee N. A comparison of shear bond strength of orthodontic buccal tubes on resin composite surface using three bonding materials. J Thai Assoc Ortho. 2005; 4(19-25.

9. Viwattanatipa N, Prasertsangwal J, Juntavee N. Weibull analysis of shear/peel bond strength of orthodontic buccal tubes bonded to five resin composites. J Orthodontic Waves. 2008; 67(3): 120-7.

10.Tezvergil A, Lassila LV, Vallittu PK. Compositecomposite repair bond strength: effect of different adhesion primers. J Dent. 2003; 31 (8): 521-5.

11. Aristidis GA. Etched porcelain veneer restoration of a primary tooth: a clinical report. J Prosthet Dent. 2000; 83(5): 504-7.

12. Castelnuovo J, Tjan AH, Phillips K, Nicholls JI, Kois JC. Fracture load and mode of failure of ceramic veneers with different preparations. J Prosthet Dent. 2000; 83(2): 171-80.

13. Mitra SB, Wu D, Holmes BN. An application of nanotechnology in advanced dental materials. J Am Dent Assoc. 2003; 134(10): 1382-90.

14. Nilsson E, Alaeddin S, Karlsson S, Milleding P, Wennerberg A. Factors affecting the shear bond strength of bonded composite inlays. Int $\mathrm{J}$ Prosthodont. 2000; 13(1): 52-8.

15. Moezizadeh M, Ansari ZJ, Fard FM. Effect of surface treatment on micro shear bond strength of two indirect composites. J Conserv Dent. 2012; 15(3): 228-32.
16.Deschepper EJ, Tate WH, Powers JM. Bond strength of resin cements to microfilled composites. Am J Dent. 1993; 6(5): 235-8.

17. Ozcan M, Cura C, Brendeke J. Effect of aging conditions on the repair bond strength of a microhybrid and a nanohybrid resin composite. J Adhes Dent. 2010; 12(6): 451-9.

18.Shahdad SA, Kennedy JG. Bond strength of repaired anterior composite resins: an in vitro study. J Dent. 1998; 26(8): 685-94.

19. Nassoohi N, Kazemi H, Sadaghiani M, Mansouri M, Rakhshan V. Effects of three surface conditioning techniques on repair bond strength of nanohybrid and nanofilled composites. Dent Res J (Isfahan). 2015; 12(6): 554-61.

20.Brosh T, Pilo R, Bichacho N, Blutstein R. Effect of combinations of surface treatments and bonding agents on the bond strength of repaired composites. J Prosthet Dent. 1997; 77(2): 122-6.

21.Pounder B, Gregory WA, Powers JM. Bond strengths of repaired composite resins. Oper Dent. 1987; 12(3): 127-31.

22.Dall'oca S, Papacchini F, Radovic I, Polimeni A, Ferrari M. Repair potential of a laboratoryprocessed nano-hybrid resin composite. J Oral Sci. 2008; 50(4): 403-12.

23. Hannig C, Laubach S, Hahn P, Attin T. Shear bond strength of repaired adhesive filling materials using different repair procedures. $\mathrm{J}$ Adhes Dent. 2006; 8(1): 35-40.

24.Loomans BA, Cardoso MV, Roeters FJ, Opdam NJ, De Munck J, Huysmans MC, Van Meerbeek $B$. Is there one optimal repair technique for all composites? Dent Mater. 2011; 27(7): 701-9.

25.Papacchini F, Dall'oca S, Chieffi N, Goracci C, Sadek FT, Suh BI, Tay FR, Ferrari M. Compositeto-composite microtensile bond strength in the repair of a microfilled hybrid resin: effect of surface treatment and oxygen inhibition. J Adhes Dent. 2007; 9(1): 25-31.

26. Fawzy AS, El-Askary FS, Amer MA. Effect of surface treatments on the tensile bond strength of repaired water-aged anterior restorative microfine hybrid resin composite. J Dent. 2008; 36(12): 969-76.

27.Lima AF, Ferreira SF, Catelan A, Palialol AR, Goncalves LS, Aguiar FH, Marchi GM. The effect of surface treatment and bonding procedures on the bond strength of silorane composite repairs. Acta Odontol Scand. 2014; 72(1): 71-5.

28. Ozcan M, Barbosa SH, Melo RM, Galhano GA, Bottino MA. Effect of surface conditioning methods on the microtensile bond strength of resin composite to composite after aging conditions. Dent Mater. 2007; 23(10): 1276-82. 
29.Swift EJ, Jr., Levalley BD, Boyer DB. Evaluation of new methods for composite repair. Dent Mater. 1992; 8(6): 362-5.

30.Swift EJ, Jr., Cloe BC, Boyer DB. Effect of a silane coupling agent on composite repair strengths. Am J Dent. 1994; 7(4): 200-2.

31.Cesar PF, Meyer Faara PM, Miwa Caldart R, Gastaldoni Jaeger R, Da Cunha Ribeiro F. Tensile bond strength of composite repairs on Artglass using different surface treatments. Am J Dent. 2001; 14(6): 373-7.

32. Wendler M, Belli R, Panzer R, Skibbe D, Petschelt A, Lohbauer U. Repair Bond Strength of Aged Resin Composite after Different Surface and Bonding Treatments. Materials (Basel). 2016; 9(7): 547.

33. Rodrigues SA, Jr., Ferracane JL, Della Bona A. Influence of surface treatments on the bond strength of repaired resin composite restorative materials. Dent Mater. 2009; 25(4): 442-51.

34.Cavalcanti AN, De Lima AF, Peris AR, Mitsui FH, Marchi GM. Effect of surface treatments and bonding agents on the bond strength of repaired composites. J Esthet Restor Dent. 2007; 19(2): 90-8.

35. Thurmond JW, Barkmeier WW, Wilwerding TM. Effect of porcelain surface treatments on bond strengths of composite resin bonded to porcelain. J Prosthet Dent. 1994; 72(4): 355-9.

36. Reynolds IR, Von Fraunhofer JA. Direct bonding of orthodontic attachments to teeth: the relation of adhesive bond strength to gauze mesh size. Br J Orthod. 1976; 3(2): 91-5.

37.Bishara SE, Vonwald L, Zamtua J. Effects of different types of light guides on shear bond strength. Am J Orthod Dentofacial Orthop. 1998; 114(4): 447-51.

38. Bradburn G, Pender N. An in vitro study of the bond strength of two light-cured composites used in the direct bonding of orthodontic brackets to molars. Am J Orthod Dentofacial Orthop. 1992; 102(5): 418-26.

39. Pashley DH, Carvalho RM, Sano $H$, Nakajima M, Yoshiyama M, Shono Y, Fernandes CA, Tay F. The microtensile bond test: A review. Journal of Adhesive Dentistry. 1999; 1(4): 299-309.

40.Shahabi S, Bagheri HG, Ramazani K. Tensile bond strength of sealants following Er:YAG laser etching compared to acid etching in permanent teeth. Lasers Med Sci. 2012; 27(2): 371-5.

41.Smith GA, Mcinnes-Ledoux P, Ledoux WR, Weinberg R. Orthodontic bonding to porcelain--bond strength and refinishing. Am J Orthod Dentofacial Orthop. 1988; 94(3): 245-52.

Yazışma Adresi:

Dr. Öğr. Üyesi Emire Aybüke ERDUR

Necmettin Erbakan Üniversitesi

Ortodonti Ana Bilim Dalı

Karaciğan Mah. Ankara Cad. No: 74/A

42050, Karatay, Konya

Tel : +903322200026/ 1240

Faks : +90332 2200045

E Posta: dtaybuke@gmail.com 